\title{
The effect of minerals on non-ionic compound sorption by changing the sorption capacity of soil organic matter
}

\author{
Ahmad G. Ahangar ${ }^{1 *}$ \\ ${ }^{1}$ Department of Soil Science, College of Agriculture, University of Zabol, Zabol, Iran. *Corresponding author: \\ a_ahangar2002@yahoo.com
}

\begin{abstract}
For non-ionic compounds, the preliminary role in the sorption process is played by soil organic matter (SOM). However, it is necessary to determine the relative contribution of soil minerals, in particular, soil clay minerals and SOM constituents, to improve prediction of the sorption process. Here, the results show that sorption capacity of SOM can be affected by mineral-SOM interaction. The organic carbon-normalized sorption coefficient $\left(\mathrm{K}_{\mathrm{oc}}\right)$ after hydrofluoric acid (HF) treatment increased an average of $124 \%$ and $98 \%$ for A11 horizons and $185 \%$ and $162 \%$ for A12 horizons for diuron and phenanthrene, respectively. We propose that the increased $\mathrm{K}_{\mathrm{oc}}$ values in the A12 horizons are due to a higher percentage of clay in A12 horizons as well as a loose connection of SOM with clay minerals in A11 horizons. We suggest that the mineral components of soil contribute greatly to sorption of even non-ionic compounds with alteration of the sorption properties of SOM, which need to be considered in determining the fate and availability of non-ionic compounds in the soil environment.
\end{abstract}

Keywords: sorption, diuron, phenanthrene, clay minerals. 


\section{Introduction}

The fate of organic pollutants, including their dissipation, mobility and degradation, generally takes place in the soil and is largely controlled by their sorption. Research during the last decade has revealed that for non-ionic compounds, the key factor to determine the extent of sorption is the organic carbon content of the soil (Kile et al., 1995; Fall et al., 2003; Ahangar et al., 2008a; Gao et al., 2007). Linear sorption processes and partitioning between the solution and soil organic matter (SOM) are most commonly used for non-ionic compounds, and the C-normalized partition coefficient $\left(\mathrm{K}_{\mathrm{oc}}\right)$ quantifies the sorption interaction (Chiou, 1989). However, in some situations, sorption interaction cannot be explained. The variability of $\mathrm{K}_{\mathrm{oc}}$ values among soils with different physical and chemical characteristics has shown the sorption of non-ionic compounds to be affected by a variety of soil properties. Therefore, SOM cannot be regarded as a sole sorbent. Previous studies (Schlautman and Morgan, 1993a; Fall et al., 2003; Huang et al., 2003; Celis et al., 2006) have shown that soil characteristics, liquid phase composition, organic matter heterogeneity and the contribution of mineral phases to sorption cause $\mathrm{K}_{\mathrm{oc}}$ variability. Although there is a general consensus that structural properties of organic matter can greatly influence its affinity for non-ionic compounds, a consensus has not been reached on the manner in which the nature of the organic matter affects sorption properties. Many studies have shown that the aliphatic group of organic matter is responsible for the sorption properties of non-ionic pollutants (Chefetz et al., 2000; Salloum et al., 2002; Chen et al., 2007). Conversely, several others have suggested that the key role is played by aromatic domains (Mao et al., 2002; Abelmann et al., 2005; Golding et al., 2005; Lixia et al., 2011).

The extent to which soil minerals can contribute to this variation remains unclear. This specific point is the focus of this paper. The potential effects of soil minerals can be surmised, although in the classical sense, SOM plays a key role in sorption of non-ionic compounds. It has been demonstrated that even in soils with high carbon content, clay minerals with 2:1 structure can be as important as SOM in sorption of non-ionic compounds. For example, it has been shown that capacities of the reference smectites to phenanthrene sorption are comparable to those of soil clays containing a significant amount of carbon content (Hundal et al., 2001).

An additional potential effect of soil minerals is their indirect influence on the sorption capacity of SOM through the blocking of SOM sorption sites or by conformational changes in the structures of organic compounds (Pusino et al., 1992; Jones and Tiller 1999; Celis et al., 2006). Thus, it has been suggested that, to some extent, soil minerals are responsible for variations in $\mathrm{K}_{\mathrm{oc}}$ between soils, although the extent to which soil minerals are responsible for these variations is less certain.

This study was conducted to provide further insight into the relative contribution of soil minerals in the sorption of non-ionic compounds. For this purpose, the sorption of phenanthrene and diuron by twelve soil surface horizons, A11 and A12 before and after HF treatment, was investigated to determine possible effects of clay minerals on $\mathrm{K}_{\mathrm{oc}}$ variation.

\section{Materials and methods}

\subsection{Soil and chemicals}

Sorption studies were conducted on Mollic Haploxeralfs soils from a paddock of approximately 2 hectares (Soil Survey Staff, 1999). The A1 horizons were subdivided into A11 and A12 horizons based on the darker colour of the former. 
Diuron and phenanthrene ( $>99 \%$ purity) were purchased from Sigma-Aldrich (Sydney, Australia). Highperformance liquid chromatography (HPLC)-grade solvents and calcium chloride were obtained from Merck Pty Ltd. (Victoria, Australia). A stock solution of $1000 \mathrm{mg} \mathrm{L}^{-1}$ of diuron and phenanthrene was prepared in methanol.

\subsection{NMR analysis}

The soils were HF-treated prior to NMR analysis using the procedure of Skjemstad et al. (1994). Solid-state ${ }^{13} \mathrm{C}$ cross polarization (CP) NMR spectra were acquired with magic angle spinning (MAS) at a ${ }^{13} \mathrm{C}$ frequency of $50.3 \mathrm{MHz}$ on a Varian Unity200 spectrometer. Samples were packed in a $7 \mathrm{~mm}$ diameter cylindrical zirconia rotor with Kel-F end-caps and spun at $5000 \pm 100 \mathrm{~Hz}$ in a Doty Scientific MAS probe. A 1-ms contact time and a 1-s recycle delay were used, and 4000 transients were collected for each spectrum. Free induction decays were acquired with a sweep width of $40 \mathrm{kHz} ; 1216$ data points were collected over an acquisition time of $15 \mathrm{~ms}$. All spectra were zero-filled to 8192 data points and processed with a $50 \mathrm{~Hz}$ Lorentzian line broadening and a 0.005 s Gaussian broadening. Chemical shifts were externally referenced to the methyl resonance of hexamethylbenzene at $17.36 \mathrm{ppm}$.

\subsection{Sorption Experiments}

Measurements were conducted in the upper two horizons (approximately 0-20 cm) of six soil cores. Sorption experiments were performed in batch incubation experiments according to OECD guidelines (OECD, 2000). To minimize changes in ionic strength and to avoid dispersion, $0.01 \mathrm{M} \mathrm{CaCl}_{2}$ was used as a background solution, and $200 \mathrm{mg} \mathrm{L}^{-1} \mathrm{HgCl}_{2}$ was used as a microbial growth inhibitor (Wolf et al., 1989; Trevors, 1996). For single point measurements, solutions of soil $(1 \mathrm{~g})$ and diuron $\left(1.5 \mathrm{mg} \mathrm{L}^{-1}, 10 \mathrm{~mL}\right)$ and soil $(0.5 \mathrm{~g})$ and phenanthrene $\left(0.8 \mathrm{mg} \mathrm{L}^{-1}, 100 \mathrm{~mL}\right)$ were shaken end-over-end for 24- and 16-hour periods, respectively. At the end of the equilibrium period, suspensions were centrifuged at $3000 \mathrm{~g}$ for 20 minutes, and $1 \mathrm{~mL}$ aliquots of the supernatant were filtered through $0.45 \mathrm{~mm}$ Teflon filters and analysed.

Diuron and phenanthrene concentrations were determined using an Agilent 1100 series HPLC equipped with a diode array detector and C18 column $(250 \mathrm{~mm}$ $\times 4.6 \mathrm{~mm}$ internal diameter, $5 \mu \mathrm{m}$ particle size). The mobile phase was $70 \%$ acetonitrile and $30 \%$ water,

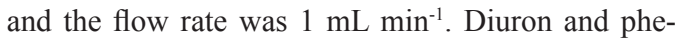
nanthrene were detected at UV wavelengths of 210 $\mathrm{nm} 254 \mathrm{~nm}$, respectively. Retention times under these conditions were 4.48 and 15.70 minutes for diuron and phenanthrene, respectively. The detection limit was $0.05 \mathrm{mg} \mathrm{L}^{-1}$ for both compounds. Blanks without diuron and phenanthrene and those without soil were analysed, and appropriate corrections were applied. Sorbed concentrations were calculated from the difference between the initial solution and equilibrium solution concentrations.

\subsection{Total Carbon Content}

Soils were analysed for total C using a LECO elemental analyser after combustion at $1650{ }^{\circ} \mathrm{C}$ and subsequent infrared detection of $\mathrm{CO}_{2}$ (Tabatabai and Bremner, 1970).

\subsection{Results and discussion}

Partitioning coefficients $\left(\mathrm{K}_{\mathrm{d}}\right.$ and $\left.\mathrm{K}_{\mathrm{oc}}\right)$ are presented in Table 1 for six core soil samples containing diuron and phenanthrene, respectively. Following the destruction of the soil mineral phase by HF treatment, $\mathrm{K}_{\mathrm{oc}}$ values were calculated again under the precise conditions used for parent materials. These values are 
presented in Table 1, and specific physical characteristics of the soil samples are presented in Table 2. For both compounds, $\mathrm{K}_{\mathrm{d}}$ values decreased with an increase in soil depth. Therefore, in all cases, $\mathrm{K}_{\mathrm{d}}$ values in the second horizons were lower than those in the first. This result was expected and has been well documented (Fall et al., 2003; Wu et al., 2011; Gao et al., 2007) because SOM is the dominant sorbent phase for non-ionic compounds.

Table 1. Sorption coefficients $\left(\mathrm{K}_{\mathrm{d}}\right.$ and $\left.\mathrm{K}_{\mathrm{OC}}\right)$ for each soil horizon for diuron and phenanthrene. Standard deviation shown in brackets. Taken from Ahangar et al. (2008).

\begin{tabular}{|c|c|c|c|c|c|c|c|c|}
\hline $\begin{array}{c}\text { Core } \\
\text { number }\end{array}$ & $\begin{array}{c}\text { Hori- } \\
\text { zon }\end{array}$ & $\begin{array}{l}\text { Depth } \\
\text { (cm) }\end{array}$ & $\begin{array}{c}\text { Kd } \\
\left(\mathbf{L} \mathbf{~ k g}^{-1}\right) \\
\text { (diuron) }\end{array}$ & $\begin{array}{c}\text { Kd } \\
\left(\mathbf{L ~ k g}^{-1}\right) \\
\text { (phenanthrene) }\end{array}$ & $\begin{array}{c}\text { Koc } \\
\text { ( } \mathrm{L} \mathrm{kg}^{-1} \text { soil C) } \\
\text { Before HF } \\
\text { (diuron) }\end{array}$ & $\begin{array}{c}\mathrm{K}_{\mathrm{oc}} \\
\left(\mathrm{L} \mathrm{kg}^{-1} \text { soil C) }\right. \\
\text { After HF } \\
\text { (diuron) }\end{array}$ & $\begin{array}{c}\text { Koc } \\
\left(\mathrm{L} \mathrm{kg}^{-1} \text { soil C) }\right. \\
\text { Before HF } \\
\text { (phenanthrene) }\end{array}$ & $\begin{array}{c}\mathrm{K}_{\mathrm{oC}} \\
\left(\mathrm{L} \mathrm{kg}^{-1} \text { soil C) }\right. \\
\text { After HF } \\
\text { (phenanthrene) }\end{array}$ \\
\hline 22 & A11 & $0-9$ & 21.3 & 1458 & $459(7)$ & $855(12)$ & $32000(3000)$ & 35000 (1000) \\
\hline 22 & A12 & $9-17$ & 10.9 & 510 & $583(2)$ & $1560(80)$ & $27000(700)$ & 49000 (2200) \\
\hline 28 & A11 & $0-5$ & 16.8 & 1044 & $473(2)$ & $1100(17)$ & $30000(800)$ & $71000(3500)$ \\
\hline 28 & A12 & $5-12$ & 10.7 & 461 & $679(25)$ & $2300(30)$ & $30000(3000)$ & $78000(2000)$ \\
\hline 30 & A11 & $0-8$ & 17.3 & 1018 & $477(12)$ & $900(40)$ & $28000(1200)$ & $45000(1400)$ \\
\hline 30 & A12 & 8-19 & 10.6 & 389 & $678(25)$ & $1600(90)$ & $25000(800)$ & $60000(4000)$ \\
\hline 33 & A11 & $0-5$ & 17.7 & 784 & $428(5)$ & $1300(80)$ & $19000(1000)$ & $55000(4000)$ \\
\hline 33 & A12 & $5-18$ & 14.8 & 348 & 707 (18) & $2500(90)$ & $16000(800)$ & $42000(1500)$ \\
\hline 35 & A11 & $0-9$ & 17.0 & 861 & $452(2)$ & $900(40)$ & $23000(1000)$ & $39000(500)$ \\
\hline 35 & A12 & $9-17$ & 8.8 & 287 & $579(15)$ & $1600(50)$ & $19000(200)$ & $65000(2300)$ \\
\hline 40 & A11 & $0-8$ & 15.0 & 764 & $405(2)$ & $850(25)$ & $20000(1000)$ & $43000(3000)$ \\
\hline 40 & A12 & 8-18 & 9.0 & 318 & $547(22)$ & $1100(30)$ & $20000(900)$ & $55000(2700)$ \\
\hline
\end{tabular}

After $\mathrm{HF}$ treatment, $\mathrm{K}_{\mathrm{oc}}$ increased an average of $124 \%$ and $98 \%$ for A11 horizons and $185 \%$ and $162 \%$ for A12 horizons for diuron and phenanthrene, respectively. The increase in the $\mathrm{K}_{\mathrm{oc}}$ values after HF treatment for both compounds clearly demons- trates the effect of the mineral phase on the sorption ability of SOM. However, it is difficult to assess the independent contribution of the mineral phase, SOM functionality and molecular structure on the $\mathrm{K}_{\mathrm{oc}}$ variation.

Table 2. Some physico-chemical characteristics of soil samples.

\begin{tabular}{ccccccccc}
\hline $\begin{array}{c}\text { Core } \\
\text { number }\end{array}$ & Horizon & $\begin{array}{c}\text { Depth } \\
(\mathbf{c m})\end{array}$ & Clay\% & Silt\% & Sand\% & pH & $\begin{array}{c}\text { CEC } \\
(\mathbf{C m o l} \\
\left.\mathbf{k g}^{-1}\right)\end{array}$ & $\begin{array}{c}\text { C content } \\
(\%)\end{array}$ \\
\hline 22 & A11 & $0-9$ & 7.5 & 27.5 & 65.0 & 5.15 & 17.3 & 4.6 \\
22 & A12 & $9-17$ & 10.0 & 30.0 & 60.0 & 5.76 & 15.1 & 1.9 \\
28 & A11 & $0-5$ & 15.0 & 27.5 & 58.0 & 5.70 & 18.5 & 3.6 \\
28 & A12 & $5-12$ & 20.0 & 25.0 & 55.0 & 6.01 & 16.0 & 1.6 \\
\hline
\end{tabular}




\begin{tabular}{ccccccccc}
\hline $\begin{array}{c}\text { Core } \\
\text { number }\end{array}$ & Horizon & $\begin{array}{c}\text { Depth } \\
(\mathbf{c m})\end{array}$ & Clay\% & Silt\% & Sand\% & pH & $\begin{array}{c}\text { CEC } \\
(\mathbf{C m o l} \\
\left.\mathbf{k g}^{-1}\right)\end{array}$ & $\begin{array}{c}\text { C content } \\
(\mathbf{\%})\end{array}$ \\
\hline 30 & A11 & $0-8$ & 12.5 & 25.0 & 63.0 & 5.65 & 16.2 & 3.6 \\
30 & A12 & $8-19$ & 15.0 & 27.5 & 57.5 & 5.81 & 11.3 & 1.6 \\
33 & A11 & $0-5$ & 12.5 & 25.0 & 63.0 & 5.86 & 19.5 & 4.2 \\
33 & A12 & $5-18$ & 15.0 & 23.0 & 63.0 & 6.09 & 16.9 & 2.1 \\
35 & A11 & $0-9$ & 12.5 & 30.0 & 57.5 & 5.25 & 18.3 & 3.8 \\
35 & A12 & $9-17$ & 15.0 & 30.0 & 55.0 & 5.80 & 15.9 & 1.5 \\
40 & A11 & $0-8$ & 15.0 & 27.5 & 57.5 & 5.70 & 17.5 & 3.7 \\
40 & A12 & $8-18$ & 15.0 & 25.0 & 60.0 & 5.83 & 16.0 & 1.6 \\
\hline
\end{tabular}

Two primary contributions for the mineral phase of soil to sorption can be considered; however, the direct contribution of soil minerals to sorption is not the focus of our study. SOM has been widely believed to be the main sorbent for non-ionic spices (Schwarzenbach et al., 1993; Kile et al., 1995; Fall et al., 2003; Ahangar et al., 2008a; Gao et al., 2007). However, for soils with less than $0.1 \%$ organic carbon content by mass, the mineral phase should be considered as a significant sorbate (Karickhoff, 1984; Schwarzenbach et al., 1993). Increases in $\mathrm{K}_{\mathrm{oc}}$ values after $\mathrm{HF}$ treatment indicate that sorptive properties of SOM and accessibility can be strongly influenced by SOM-mineral interaction. In addition, soil clay minerals can affect the sorption characteristics of the entire soil unit by reducing the sorption capacity of organic components. We propose that bound organic compounds with minerals, and in particular, hydrophobic domains of SOM are less accessible to diuron and phenanthrene. Our finding is consistent with that of previous research that proposes the extent of organic matter contribution to the sorption process is influenced by association mechanisms between the mineral phase and soil organic constituents. Therefore, in this condition, the organic phase is less accessible to organic pollutants (Pusino et al., 1992; Jones and Tiller, 1999). Several researchers have observed that sorption of hydrophobic organic chemicals by humic and fulvic acids are reduced in the presence of aluminium and iron oxides. They hypothesized that strong ligands of solid organic matter with mineral surfaces prevent the organic matter from sorbing the organic pollutants (Schlautman and Morgan, 1993b; Laird et al., 1994).

Moreover, we propose that bound organic matter within the mineral phase can cause reduction in the accessibility of the hydrophobic domains of SOM. Similarly, it has been demonstrated that the association of mineral phase and SOM could result in tight aggregation and limitations in organic matter sorption site accessibility for aqueous-phase organic pollutants (Njoroge et al., 1998).

Figure 1 shows the proportion of $\mathrm{K}_{\mathrm{oc}}$ in $\mathrm{A} 12$ horizons to A11 horizons for phenanthrene and diuron. In most cases, increases in the $\mathrm{K}_{\mathrm{oc}}$ values for $\mathrm{A} 12$ horizons are higher than those for A11 horizons for both compounds. We propose that the higher $\mathrm{K}_{\mathrm{oc}}$ values in the A12 horizons are due to a higher percentage of clay in A12 horizons as well as loose connection of SOM with clay minerals in A11 horizons. 
A: phenanthrene

口Before H treanent aAfter HFtreatrent

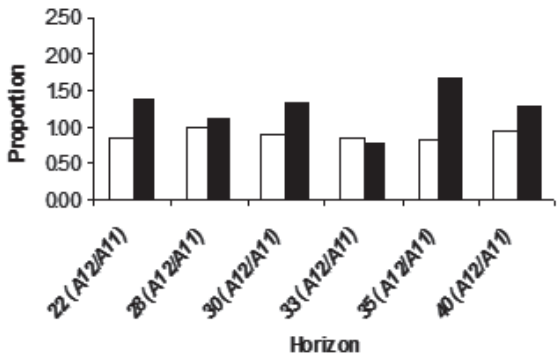

B: Diuron

口Before HFtreatrent $\mathbf{a}$ After H Ftreatrment

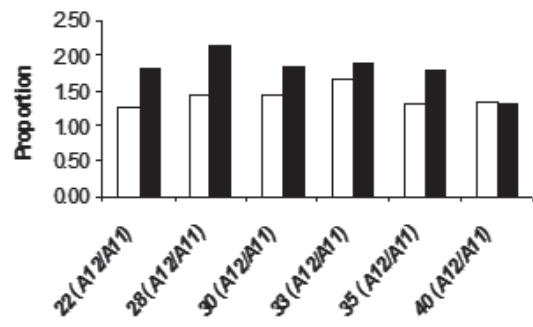

Horizon

Figure 1. Proportion of A12 Koc to A11 Koc before and after HF treatment for henanthrene (A) and Diuron (B).

Figures 2 and 3 show a connection between $\mathrm{K}_{\mathrm{oc}}$ alteration before and after HF treatment and particle size. The changes in $\mathrm{K}_{\mathrm{oc}}$ values can be justified by the percentage of clay minerals: $r^{2}=0.43$, significance level $<0.01$ and $\mathrm{r}^{2}=0.26$, significance level $<0.07$, respectively, for phenanthrene and diuron. The weak relationship between $\mathrm{K}_{\mathrm{oc}}$ alteration and clay minerals indicates that the clay content of soils is an influential factor on $\mathrm{K}_{\mathrm{oc}}$ variation, in addition to the intimate and complicated association between clay minerals and organic compounds. Therefore, the effect of organic pollutants on this relationship should be considered.

These findings strongly demonstrate that the extent of soil sorption affinity for the given organic compounds is strongly dependent on the organic matter content. In addition, soil mineral matter exerts influence on alteration of the sorption characteristics of SOM. Although it is not an easy task to evaluate the independent contribution of the mineral phase in the entire sorption process, it is a priority for research in the area of sorption.

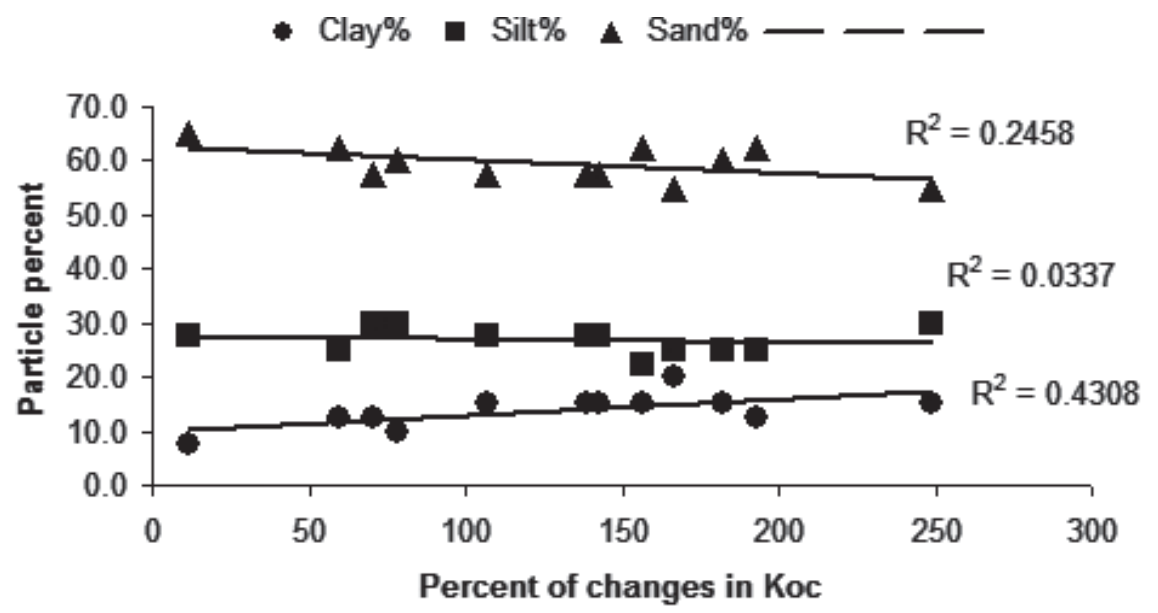

Figure 2. Relationship between percent of sand, silt and clay and changes in Koc before and after HF treatment for phenanthrene. 


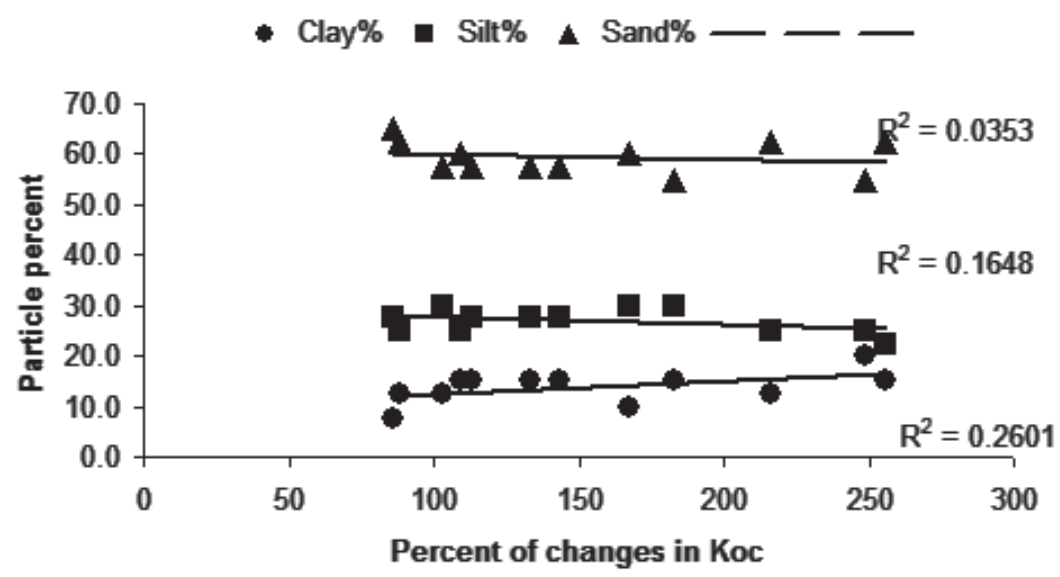

Figure 3. Relationship between percent of sand, silt and clay and changes in Koc before and after HF treatment for diuron.

\section{Conclusion}

SOM is important in the process of non-ionic compound sorption, although sorption cannot be predictable exclusively from the organic matter content of soils. Improved prediction of sorption of non-ionic compounds in soils requires a better understanding of the relative contribution of mineral and organic soil components to the sorption process. The increased $\mathrm{K}_{\mathrm{oc}}$ values after $\mathrm{HF}$ treatment is higher for the A12 horizons than those for A11 ones. We suggest that alteration of the sorption properties of SOM by the mineral components of soil should be taken into account as the main reason. The findings of this study showed that HF-treatment can increase soil $\mathrm{K}_{\mathrm{oc}}$ for diuron and phenanthrene, and attributed this to organic mattermineral interactions that block organic matter sorption sites in the whole soils. Thus it can be suggested that suitable descriptors for the extent of organic matter-mineral interactions would help to improve current $\mathrm{K}_{\mathrm{oc}}$-based sorption predictions, which in turn can improve the assessment of risk associated with the presence of non-ionic pollutants in soil.

\section{References}

Abelmann, K., Kleineidam, S., Knicker, H., Grathwohl, P., Kogel-kanber, I. 2005. Sorption of HOC in soils with cabonaceous contamination: Influence of organic-matter composition. J.Plant Nutr. Soil Sci. 168, 293-306.

Ahangar, A.G., Smernik, R.J., Kookana, R.S., Chittleborough, D.J. 2008. Separating the effects of organic matter-mineral interactions and organic matter chemistry on the sorption of diuron and phenanthrene. Chemosphere. 72, 886-890.

Celis, R., De Jonge, H., De Jonge, L.W., Real, M., Hermosin, M.C., Cornejo, J. 2006. The role of mineral and organic components in phenanthrene and dibenzofuran sorption by soil. European journal of soil science. 57, 308-319.

Chefetz, B., Deshmukh, A.P., Hatcher, P.G., Guthrie, E.A. 2000. Pyrene sorption by natural organic matter. Environ. Sci. Technol. 34, 2925-2930.

Chen, D., Xing, B., Xie, W. 2007. Sorption of phenanthrene, naphthalene and o-xylene by soil organic matter fraction. Geoderma. 139, 329-335. 
Chiou, C.T. 1989. Theoretical considerations of the partition uptake of nonionic organic compounds by soil organic matter. Reactions and movement of organic chemicals in soils. B. L. Sawhney and K. Brown. Madison,WI, Soil Science Society of America. Inc, 1-29.

Fall, C., Chaouki, J., Chavarie, C., Elena-Ortega, R. 2003. Multivariate study on phenanthrene sorption in soils. Journal of environmental engineering. 129, 1030-1040.

Gao, Y., Xiong, W., Ling, W., Wang, X., Li, Q. 2007. Impact of exotic and inherent dissolved organic matter on sorption of phenanthrene by soils. Journal of hazardous material. 140, 138-144.

Golding, C.J., Smernik, R.J., Birch, G.F. 2005. Investigation of the role of structure domains identified in sedimentry organic matter in the sorption of hydrophoboc organic compounds. Environ . Sci. Technol. 39, 3925-3932.

Huang, W., Peng, P., Yu, Z., Fu, J. 2003. Effects of organic matter heterogeneity on sorption and desorption of organic contaminants by soils and sediments. Applied Geochemistry. 18, 955-972.

Hundal, L.S., Thompson, M.L., Laird, D.A., Carmo, A.M. 2001. Sorption of phenanthrene by reference smectites. Environ . Sci. Technol. 35, 3456-3461.

Jones, K.D., Tiller, C.L. 1999. Effect of solution chemistry on the extent of binding of phenanthrene by a soil humic acid: A comparison of dissolved and clay bound humic. Environ . Sci. Technol. 1999, 580-587.

Karickhoff, S.W. 1984. Organic pollutant sorption in aqeous system. J. Hydraul.Eng. 110, 707-735.

Kile, D.E., Chiou, C.T., Zhou, H., Li, H., Xu, O. 1995. Partition of nonpolar organic polltants from water to soil and sediment organic matter. Environ . Sci. Technol. 29, 1401-1409.

Laird, D.A., Yen, P.Y., Koskinen, W.C., Steinheimer, T.R., Dowdy, R.H. 1994. Sorption od atrazine on soil clay components. Environ . Sci. Technol. 28, 1054-1061.

Lixia, J., Mengchang, H., Jinghuan, Z., Xinghui, X. 2011. Norfloxacin sorption to different fractions in sediments from typical water systems in China. Soil and Sediment Contamination. 20, 564-580

Mao, J.D., Hundal, L.S., Thompson, M.L., Schmidt Rohr, K. 2002Correlation of poly(methylene)rich amorphous aliphatic domains in humic substances with sorption of a nonpolar organic contaminant, phenanthrene. Environ . Sci. Technol. 36, 929-936.

Njoroge, k.B.N., Ball, W.P., Cherry, R.S. 1998. Sorption of 1,2,4-trichlorobenzene and tetrachloroethene within an authigenic soil profile: Changes in Koc with soil depth. Journal of contaminant hydrology. 29, 347-377.

OECD, 2000. Adsorption/desorption using a batch equilibrium method, test guideline 106. OECD guidelines for testing chemicals, OECD publications, Paris.

Pusino, A., Liu, W., Gessa, C. 1992. Influence of organic matter and its clay complexes on metolachlor adsorption on soil. Pestic.Sci. 36, 283-286.

Salloum, M.J., Chefetz, B., Hatcher, P.G. 2002. Phenanthrene soption by aliphati-rich natural organic matter. Environ . Sci. Technol. 36, 1953-1958.

Schlautman, M.A., Morgan, J.J. 1993a. Effect of aqueous chemistry on the binding of polycyclic aromatic hydrocarbons by dissolved humic acid. Environ . Sci. Technol. 27, 961-969.

Schlautman, M.A., Morgan, J.J. 1993b. Binding of fluorescent hydrophobic organic probe by dissolved humic substances and organically-coated aluminum oxide surface. Environ . Sci. Technol. $27,2523-2532$.

Schwarzenbach, R.P., Gschwend, P.M., Imboden, D.M. 1993. Environmental organic chemistry. New York, Wiley-In-terscience. 
Skjemstad, J.O., Clarke, P., Taylor, J.A., Oades, J.M., Newman, R.H. 1994. The removal of magnetic materials from surface soils. A solid state $13 \mathrm{C} \mathrm{CP} /$ MAS n.m.r. study. Aust. J. Soil Res. 32, 1215-1229.

Soil Survey Staff. 1999. Soil Taxonomy. 2nd ed. United States Department of Agriculture, Natural Resources Conservation Service, Washington DC.

Tabatabai, M.A., Bremner, J.M. 1970. Use of the Leco automatic 70-second carbon analyzer for total carbon analysis of soils. Soil Sci.Soc. Am. Proc. 34,608-610.

Trevors, J.T. 1996. Sterilization and inhibition of microbial activity in soil. J.Microbiol.Methods. 26, 53-59.
Wolf, D.C., Dao, T.H., Scott, H.D., Lavy, T.L. 1989. Influence of sterilization methods on selected soil microbiological, physical and chemical properties.J.Environ.Qual. 18, 39-44.

Wu, X. M., Li, M., Long, Y.H., Liu, R. X., Yu, Y.L., Fang, H., Li, S. N. 2011. Effects of adsorption on degradation and bioavailability of metolachlor in soil. Journal of Soil Science and Plant Nutrition. $11,3,83-97$. 
